Journal Home Page:

http://perlinguam.journals.ac.za

\section{Per Linguam}

A Journal for Language Learning Tydskrif vir Taalaanleer

\title{
FROM 'ENGLISH-ONLY' TO TRANSLANGUAGING STRATEGIES: EXPLORING POSSIBILITIES
}

Nangura Mwinda, teacher for the Namibian Department of Education Christa van der Walt, Stellenbosch University

This article investigates English language proficiency development in a rural primary school in the Kavango region of Namibia. English is the language of instruction in most schools in Namibia from fourth grade onwards. In addition to other challenges, lack of adequate proficiency in English has been identified as one of the major barriers to learning. Current research on translanguaging demonstrates that purposeful use of translanguaging supports learning. The aim of this article is to argue that a contextual analysis and a test of learners' proficiency in their dominant language and in English are essential when deciding on translanguaging strategies. This may lead to possible ways in which translanguaging can improve the English language proficiency of rural primary learners in an environment where the language is hardly heard or spoken outside the classroom. The paper argues that translation, and preview - view - review strategies are some of the translanguaging teaching strategies that could be used as resources for building English vocabulary.

Key words: education policy, English-only, English proficiency, Namibian primary schools, translanguaging.

\section{INTRODUCTION}

There are about thirty languages spoken in Namibia, fourteen of which are national languages ${ }^{\mathrm{ii}}$ with English as the sole official language of the country. Being the primary language of the country, English performs various roles especially in educational institutions; as the Language of Learning and Teaching (LoLT), as the language in which all the examinations are conducted (except first language as a subject), and as a compulsory subject from the first to the twelfth grade. Although the Language-in-Education Policy (LEP) mandates the use of English as the primary Language of Learning and Teaching (LoLT) in most schools in Namibia, the language is hardly heard or used in rural communities.

The Language-in-Education Policy (LEP) of Namibia (Wolfaardt, 2005: 2358) adopts an 'earlyexit transitional' bilingual education model whereby learners get some first language (L1) instruction before moving on to English as the LoLT. In the early primary school years (grades 1-3), learners are taught using first languages (L1s) ${ }^{\text {iii }}$ as the primary Languages of Learning and Teaching and then switch to English-only (as LoLT) from fourth grade onwards. Unlike in urban schools where learners get more exposure to English, most rural primary school learners 
encounter English only in the classroom and their English language proficiency is perceived to be far weaker than that of learners in urban schools. This state of affairs prevents learners from understanding not only English as a subject, but also other subjects that are taught and written in English (Harris, 2011: 7; Iyambo, 2011: 14; Wolfaardt, 2004: 370).

This challenge is not specific to Namibian rural primary schools, but is experienced elsewhere in Africa as well. For instance, Brock-Utne (2007: 512) in her study on language of instruction and student performance in Tanzania and South Africa, shows that insufficient competency in the LoLT is the main factor contributing to academic under-achievement as well as low education standards. Scholars such as Wilson and Komba (2012: 9); Clegg and Afitska (2011: 73); Stephen, Welman and Jordaan (2004: 51) and Vinke and Jochems (1993: 281) also show in their studies that a lack of adequate proficiency in the Language of Learning and Teaching is an additional barrier to both teaching and learning which makes the previous academically disadvantaged groups even more disadvantaged.

Although the Namibian LEP supports the use of local languages alongside English, this principle is not embraced fully by many schools (Murray, 2007: 76). In the experience of the first author of this article, the current situation is that the first language (L1) is used mainly as the LoLT; in the case of the learners in this study, Rumanyo. Like the teachers in Probyn's study (2001: 262), there is the feeling that teaching through the medium of English can be described 'variously as a burden, and of dragging, hooking, and pulling the students'. In such cases translanguaging (see discussion below) occurs in various forms and the first language can become a resource to foster understanding. Although there are strategies to improve learners' English language, there is a dearth of research on the possibilities for translanguaging strategies to be used to improve English language proficiency. We seek to explore these possibilities in this study.

In the sections that follow the context within which translanguaging strategies such as translation and code switching can occur will be discussed. Based on learners' dominant language and teachers' existing code-switching practices, the argument is made that these translanguaging practices may be extended to support language and academic development.

\section{THE STUDY AREA AND PARTICIPANTS}

This study was conducted in a combined school (referred to as CSX in this article). CSX is a school situated about $180 \mathrm{~km}$ east of Ndiyona constituency in the Kavango East region. The school is located in a multilingual context with more than two community languages, namely Runyemba $^{\text {iv }}$, Rugciriku ${ }^{v}$ and Thimbukushu. Most of these multilingual learners use English at school, but the other languages for communication inside and outside the school. For this reason, one of the purposes of this project is to highlight the interdependency of languages in their development. The population already has a lingua franca (Rumanyo - see the note on Rugciriku above) and therefore English is not needed for communication purposes. Although English is barely heard or used in this community, it is the Language of Learning and Teaching as required by the Language Policy for schools in Namibia (Ministry of Education and Culture, 1993: 63). The multilingual context, where teachers and learners code switch in classrooms, is regarded as one of the elements that create possibilities for translanguaging. 
This was a small-scale study because of the size and the location of the school. Although this is a school that serves four towns, each grade has fewer than twenty learners. The participants in this study were eight grade 7 learners and seven teachers. The focus was on grade 7 for two reasons:

- Grade 7 learners are in their last primary grade before entering Junior Secondary Education level and,

- It is the only primary grade that, in terms of the Language-in-Education Policy, requires learners to demonstrate adequate proficiency in LoLT in order for them to flourish at the next education level.

The following section will describe the theoretical context of the study.

\section{THEORETICAL CONTEXT}

Translanguaging is a relatively new and developing term that was coined by Cen Williams and his colleague Dafydd Whittal during their in-service training for deputy head teachers in Llandudno, North Wales (Lewis, Jones and Baker 2012: 643). The term translanguaging is well known for this historical conception; helping to ease the language conflict that arose between English, the dominant language, and Welsh, the endangered language. In this case translanguaging strategies in a bi-/multilingual context help the language user to view both languages as important and effective rather than favouring the dominant language. For this reason, translanguaging can play the role of giving low status languages a voice in education. In educational institutions, translanguaging encourages and liberates learners to learn in a low status language and produce what they have learnt in the dominant language, or the other way round. Lewis, Jones and Baker (2012: 643)point out that translanguaging was first known by the Welsh word "Trawsiethu" in Welsh schools to describe the pedagogical practice where students systematically shift from one language to another for specific reasons, for example reading in one language and discussing the text in another, or listening to one language and writing in another.

In a traditional bilingual education context, translanguaging can be seen as problematic. The original and main emphasis of bilingual education is for learners to demonstrate native-like competency in both languages so as to learn the subject content with comprehension in either of the languages (according to the definition of bilingual education in Baker, 1993: 9). In terms of this traditional conception of bilingual education, languages are developed separately in various constellations. A strict separation of languages, called language arrangements by García (2009: 291), occurs. The separation can be in terms of class time, subject, classroom or teacher. For example, there will be separate classrooms and teachers for particular languages or some subjects (like Mathematics) will be taught in a dominant language.

However, recent neurolinguistic studies show that when bilinguals use one of their languages, both of the languages remain active (Thierry and $\mathrm{Wu}, 2007$; Hoshino and Thierry, 2011). As an umbrella term, translanguaging is useful in bilingual contexts since it describes the usual and normal practice of bilinguals without diglossic functional separation (García, 2009: 45). In other words, bilinguals do not use their languages separately. García (2009: 298) notes that 
translanguaging is like a four-wheel-drive vehicle that can negotiate a wide variety of (language) terrains. Acknowledging that multilinguals do not separate their languages when they interact with other multilinguals has major implications for bilingual education. This implies a degree of flexibility in teaching that monolingual teachers may not always be ready to accept. It also implies acceptance of strategies like code switching, a teaching and learning strategy that has been regarded as unsuitable for education purposes (Auerbach, 1993). Given the negative and outdated perception of bilingualism which suggests that using more than one language in the classroom causes confusion and cognitive deficit, Lewis, Jones and Baker (2012: 642) explain that 'the creation of translanguaging in bilingual education can be seen as emancipation from the early negative notions concerning bilingualism'.

The use of translanguaging strategies in bilingual classrooms has advantages for bilingual programmes (Hornberger and Link, 2012: 242), since it promotes metalinguistic awareness (Thierry and Wu, 2007; and Hoshino and Thierry, 2011). García (2009: 151) states that translanguaging in bilingual classrooms helps to facilitate effective learning of content and languages and it can help educators, students and other education stakeholders to see that translanguaging:

- Challenges monolingual assumptions that permeate current language education policy and instead treats bilingual discourse as the norm;

- Refers to pedagogical practices that use bilingualism as resource, rather than ignoring it or perceiving it as a problem;

- Goes beyond traditional notions of bilingualism and second language teaching and learning; and

- Describes the practices of all students and educators who use bilingualism as a resource.

Following on the above characteristics of translanguaging, it is clear that it needs to be investigated as an overarching concept that includes a variety of practices meant to promote deeper and fuller understanding of subject matter. A range of translanguaging strategies, from code switching to co-languaging and translation (to mention a few) can encourage learners to use their stronger language to develop proficiency in their weaker language (Baker, 2006: 297); and to develop metalinguistic awareness.

Although much has been written on the concept of translanguaging, and on examples of translanguaging practices in classes (for example, Shohamy, 2006: 83 and García, 2009: 156), reports on systematic use of such practices for teaching and learning have been published only recently. Blackledge and Creese (2010) offer some hints for a translanguaging pedagogy (beyond code switching) by noting in their classroom observations that a teacher "narrates the story in Mandarin, keeping to the storyline. She explains the story in English, emphasising the story's moral tale'. Another strategy is that 'the term is given in one language and explained in another language' (Blackledge and Creese, 2010: 111, 112). From their list of examples of 'flexible bilingualism and flexible pedagogy' (Blackledge and Creese, 2010: 112, 113), the best suggestions for the Namibian context seem to be:

- Use of bilingual label quests, repetition, and translation across languages; 
- Endorsement of simultaneous literacies and languages to keep the pedagogic task moving; and

- Use of translanguaging for annotating texts, providing greater access to the curriculum, and lesson accomplishment.

In terms of teacher development, the only (to the best of our knowledge) translanguaging guide for teachers has been developed by Celic and Seltzer (2011). Their guide starts with the school environment, collaborative work and multilingual resources. They then offer strategies for content and literacy development, including strategies like preview - view - review, multilingual research, comparing multilingual texts and reading and responding to multilingual texts (Celic and Seltzer, 2011: 100-118), to name a few. In view of the scope of the current project, only some of the many strategies available could be attempted, as will be explained next.

\section{DESIGN OF THE PROJECT}

As mentioned previously, the school in which this study was done is a small school. There were eight grade 7, rural, primary-school learners. The project was a qualitative study that included observations, interviews, an attempt to use translanguaging strategies with a particular class and some numerical data (in the form of learners' marks). Ethical clearance for the study was obtained from Stellenbosch University (as the institution where the study was supervised) the Namibian education authorities, the school principal, teachers and learners' parents and guardians. Learners gave assent to participate anonymously.

In the discussion that follows, the focus will be on learners' proficiency in Rumanyo and English and the implications of their proficiency for possible translanguaging practices. Although some reference is made to findings regarding observations and interviews, these will not be reported on in detail in this article.

With a view to determining what role Rumanyo played in the school itself, learners were observed on the school grounds and in the classrooms and the teachers were interviewed. It seemed necessary to determine language practices and teacher attitudes before trying out particular translanguaging practices. Teachers were interviewed about their code-switching practices and about the state of affairs regarding English language teaching and the use of other languages at this school. Observations yielded evidence of extensive code switching, illustrating firstly that teachers made use of code switching, but in a seemingly random and unplanned way. As was the case in CSX, conversational code switching is a widespread practice to facilitate understanding in schools where the LoLT is not used for communication outside the classroom (see Rose and Van Dulm, 2006; Setati et al., 2002). As pointed out by Van der Walt, Mabule and De Beer (2001), there is a need for responsible code switching to improve academic language proficiency. Although learners' understanding may improve with unplanned or random code switching, their expression in the LoLT may not improve without more responsible and focused code-switching practices. In addition to investigating the context, it was also important to compare the language proficiency of the learners in Rumanyo and English to determine the extent to which Rumanyo could be used to support the learning of English. We argued that 
improving the English vocabulary of the Namibian learners seemed important as a first step in increasing competence in English and therefore a direct translation and comparison of words in both languages seemed important.

In order for this project to seek broader and better understanding about issues surrounding English language proficiency development and the possibilities which exist for translanguaging teaching strategies in an English rural primary classroom, different data collection tools were used namely, a Rumanyo-to-English translation test, an attempt to use translanguaging teaching strategies (see below), and English-to-Rumanyo translation test. Ways in which the mentioned data collection tools were used are explained below.

\section{Rumanyo-to-English and English-to-Rumanyo translation tests}

In these vocabulary tests the focus was on everyday words and it was administered to the grade 7 learners at the visited school. Learners were first asked to read a given text (which was written in Rumanyo) and then interpret it in English and two days later another text was given in English and learners had to interpret it in Rumanyo. The purpose was to see the proficiency level of these learners in both languages with translations in both directions. It was necessary to test both languages in order to determine the extent to which Rumanyo could possibly support learning in English.

\section{Attempt to use possible translanguaging teaching strategies to support vocabulary development}

The purpose of this study was not to improve language proficiency, but to provide a snapshot of a context where translanguaging could be a resource for the development of English language proficiency, particularly in terms of vocabulary development. The attempt to use translanguaging teaching strategies consisted of presenting learners with everyday English and Rumanyo words. Translanguaging teaching strategies included the use of picture vocabulary words (Rumanyo words alongside English as shown in the picture below) and the preview - view - review approach as described by García (2009: 301). The preview - view - review teaching strategy was used because it allowed the first author to make use of learners' first language (L1) in the preview phase of the lesson as a resource to help them understand the content, described by García (2009: 301). This kind of planned code switching would meet the requirements of what Van der Walt et al. (2001) call responsible code switching, as opposed to random or conversational code switching. The approach was meant to help learners to use their strong language (Rumanyo) and build on or support English development.

Based on this strategy, Rumanyo (L1) was used to introduce (preview) what is expected in the lesson, followed by the prepared lesson in English (view) and lastly both languages were used in review activities. As mentioned earlier, the purpose of this study was not to improve language proficiency, but to search for existing bilingual strategies that might help learners enhance their proficiency in English and understand the content. This type of code switching, which requires careful planning, could build on teachers' existing, inter-sentential code-switching practices. In the two sessions taught, learners' L1 and pictures were used alongside English, in order to help learners understand the subject content in English. By the end of each session, learners were asked to construct sentences in both languages (orally).

Per Linguam 2015 31(3):100-108

http://dx.doi.org/10.5785/31-3-620 


\section{RESULTS}

\section{Rumanyo to English translation test}

Every grade 7 learner ${ }^{\mathrm{vi}}$ was given a Rumanyo text created using everyday words from four domains: family, school, friends and nature (see Table 1 below). Before the text was distributed to learners, it was explained what was expected from them. The learners were told to read the text (left-hand column below), understand what the text is all about, and then rewrite or translate it into English without changing the content. Below is a typical example of a learner's response in English (right-hand column). The possible English translation of the text is provided below the two columns.

\begin{tabular}{|c|c|}
\hline The Rumanyo text given to learners & Learners' translated text (in English) \\
\hline $\begin{array}{l}\text { Mu mayuva } 21 \text { gha mwedi wa } \\
\text { Nkurupemba vakurona } \\
\text { kwandongirilire vikushongita navintje } \\
\text { nakuntindikida kushure. } \\
\text { Murongi aka ntura pashitafure osho a } \\
\text { rongikidire navikushongita yira } \\
\text { shitjangito sha inka, shalikara, } \\
\text { shidongonito, Shitaulito na mbapira } \\
\text { dakuvarura. Pakurupuka kushure atwe } \\
\text { kuyendera muvitondo vyamundulye } \\
\text { dogoro katika kumundi. Kumundi, } \\
\text { vakuruvande vayenda mushitand oko } \\
\text { vana kateta Mushoni wana ngondwe } \\
\text { ngava ghulite ngava mfutire kushure, } \\
\text { nampiri moomo vaghu shweneka vaka } \\
\text { likungontjitwe }\end{array}$ & $\begin{array}{l}\text { The date of } 21 \text { July my mother and my } \\
\text { father her took me a lot os of things that I } \\
\text { want to used to school when the schoo my } \\
\text { teacher shestell me that come and sit to } \\
\text { your table and I put your thing to my table } \\
\text { the things like pencel,pen, rabber, ruller } \\
\text { and text book. when I out to school we a } \\
\text { waki in the treeup to my home.my sisters } \\
\text { going to the bush and cut the grass to seli } \\
\text { and to give me a money for school find } \\
\text { but concevence shes tell me don't cut that } \\
\text { grass (Learner A). } \\
\text { In the days in month of July my perent } \\
\text { were sent me at school and my teacher her } \\
\text { or she teike me to sit in the classroom. Bat } \\
\text { I heve something lake pencel, pen and } \\
\text { raber, ruler and text book for mr to sued } \\
\text { of some of my perents the was go in the } \\
\text { Bush to cat the grass wich is neme is } \\
\text { nangondwe. bat iven the forestry are don't } \\
\text { wan't some people to cat some the grass. } \\
\text { bat were wont to pay the mone that grass } \\
\text { they wan't to get some mone to pay the } \\
\text { school fands for me. wen were came beck } \\
\text { with my own freand is moving at the } \\
\text { other said of the rot at the people } \\
\text { (Learner B). } \\
\text { The date for } 21 \text { month July my parent } \\
\text { teach me everything for you sing at } \\
\text { school. At school teach she put me at the }\end{array}$ \\
\hline
\end{tabular}

Per Linguam 2015 31(3):100-108

http://dx.doi.org/10.5785/31-3-620 


\begin{tabular}{|l|l|}
\hline & $\begin{array}{l}\text { chockbot for me. which lots of } \\
\text { pen,pensil,rubber and book for reading. } \\
\text { When the school is out. Then will go to } \\
\text { tree wolked at home.my parent she is } \\
\text { going at bush and cut gras and sell it ana } \\
\text { pay for me school fant conisevesi is not } \\
\text { want fo cat a grass (Learner C). }\end{array}$ \\
\end{tabular}

\section{The possible or suggested translated text}

On the 21 st of July, my parents prepared all the materials for me to start school. At school, the teacher assigned me a desk which was prepared with learning materials such as a pen, pencil, an eraser, a ruler and text books. After school hours, we walked home under shade trees. But at home, my siblings had gone to the bush to cut thatch grass, to sell and pay my school fees, despite the nature conservancy protecting it.

\section{Table 1: Rumanyo-to-English translation}

\section{Analysis of the translation scripts}

In an attempt to compare learners' translations, marks were awarded using the following methods:

Step one: Two columns were created next to each sentence for every learner so that problems with translation $(\mathrm{T})$ could be separated from problems with understanding and interpreting the text (I).

Step two: The possible translated text was used as a guide to allocate marks. For example, learners' work was compared to the guide and a tick or cross in each column indicated the success of their writing. In this case, a tick was used to show that learners got the sentence right (translated with reasonable accuracy); while a cross was used to show that learners had not translated the text comprehensibly.

Step three: First, all the ticks were added in one column (per learner), the total number of ticks was obtained and then this total was divided by the total number of sentences from the text. The answer obtained, multiplied by hundred and the given answer was the percentage allocated to each learner. For example, LA scored seven ticks under column T. The seven ticks divided by twenty one (which is the total number of sentences), multiplied by hundred, provided a score of thirty three percent $(33 \%)$. While this formula may not be a perfect instrument, it was adopted since a strategy was needed to compare learners' performance in a way that took the amount of writing into account.

The same procedure as described above was followed to award marks under column I, which represents learners who did not translate the text accurately but understood what the text meant. 
The bar chart below is a representation of both $\mathbf{T}$ (translation with accuracy) and $\mathbf{I}$ (not translating the text accurately, but having an idea about what the text meant). Using procedures enumerated in stages $1-3$ above, the following scores were obtained:

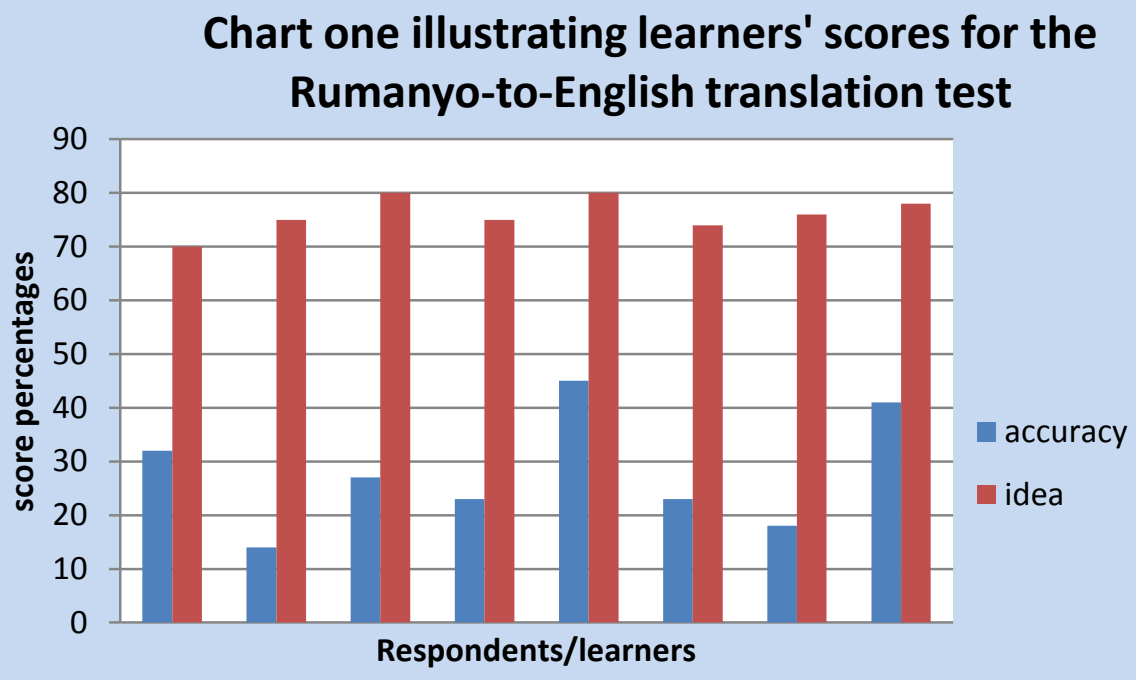

Graph 1: Illustration of Learner's ability to translate and express ideas from Rumanyo in English

On the one hand, as illustrated in Graph 1 above, most learners scored below 50\% for the accuracy of his/her translation. On the other hand, those who had an idea about what the text meant, but could not fully translate it into English, scored above sixty per cent (60\%). This means that learners understood the text, but they were unable to communicate the ideas with some degree of accuracy. The question is what stopped learners from translating or expressing themselves accurately? After closely considering learners' written scripts, some factors emerged, mainly associated with the inability to understand issues related to language structure (syntax), for example direct translation, the inappropriate use of tenses, lack of verb agreement and spelling problems. How each of the above-mentioned factors affects learners' translations is discussed in the following sub-sections.

\section{* Language structure (syntax)}

Learners were not sure of how to put the words together to construct meaningful sentences. Examples can be seen in Learner 2 and Learner 3's translations.

- L2: The was go in the bush. This sentence was meant to communicate the following idea: They went into the bush.

- L2: Bat were won't to pay the mone that grass they wan't to get same mone to pay she school farnds for me. The idea the learner wanted to present in this sentence was: They went to cut grass to sell to pay their school fees. 
- L3: school teaching and put in the choackboard for me this and giving me writing like pencil pen clean ruler textbook after noun to school their going to the three up to home. By writing this, L3 meant to communicate these ideas: At school the teacher assigned me a desk and gave me items like a pencil, a pen, a ruler and textbook. After school hours, we walked home under shady trees.

\section{Direct translation from the first language}

A factor that prevented learners from communicating their ideas in fluent English was the tendency to translate directly from Rumanyo (L1) to English. In Rumanyo the word order for expressing the date is different from English. For instance, the word order for expressing the date in Rumanyo is as follows:

\begin{tabular}{|c|c|c|c|}
\hline Days (preposition) & Exact days & The month & The year \\
\hline $\begin{array}{l}\text { Mumayuva (in, on ) } \\
\text { Literally means: in or } \\
\text { on the days }\end{array}$ & Murongo (ten) & $\begin{array}{l}\text { Gha mwedi wa } \\
\text { Nkurupemba. } \\
\text { Literally or directly } \\
\text { means the month of } \\
\text { July }\end{array}$ & $\begin{array}{l}\text { Mwaka wa } \\
2013=\text { the year } \\
\text { of } 2013\end{array}$ \\
\hline
\end{tabular}

Table 2: Learners' translation techniques

From the examples above, it is evident that the following learners (represented by numbers L1, L2 and L3) wrote or expressed the wording "on the 21 July" in Rumanyo as shown below:

- L1: In the days 21 in month of July.

- L2: In day 21 of July.

- L3: In date for 21 month for July.

Since learners used the linguistic structure of Rumanyo in English, they altered the meaning which they intended to communicate. This is because learners were borrowing words from Rumanyo and using them in English as can be seen in the following sentences:

- L1: my sisters going to the bush and cut the grass to seli...

- L2: grass wich is neme is nangondwe bat iven the forrestry are don't wan't...

- L5: Run this tree and this tree until home.

- L6: ...everything for you sing at school.

In the sentences presented above (especially L1 and L2), learners used the i-inflection which is used for verbs in Rumanyo. Besides the i-inflection, learners borrowed words from Rumanyo and used them in English. An example can be seen in L6, where the learner's translation said sing at school. In Rumanyo, the word sing has two different meanings: one can use the word sing to refer to making musical sounds with the voice and to refer to learning at or attending school. 


\section{The use of tense}

When it comes to the use of tense, learners lack familiarity with the correct use of tense, in this case past tense. Most learners rewrote the text using a mixture of present, present continuous or future tense verb forms, for example

- My teacher shes tell me that came and sit...

- My techer he or she teike me to sit...

- My parent taiking me at school...

Based on results from both tests, lack of correct use of appropriate tenses with proper verbs, nouns and pronouns, among others, is not due to the influence of either languages, but is rather due to the incomplete representation of English grammar in learners' minds.

\section{* Spelling mistakes}

Apart from the incorrect use of tense, verb agreement and syntax, spelling mistakes constitute one of the major factors that may make it hard for readers to understand what learners wanted to communicate. For example, learners spelt some words incorrectly as underlined in the sentences below:

- L1: but concevence estell me don't cut that grass.

- L2: bat iven the forestry are don't wan't.

- L3: after noun to school their going their and cut.

- L4: bother going to shitanda and cat grass and ngondwe and fanding and tori poto the school fat.

- L5: My brother its going at bush to cart the grass even the forestry is angry.

- L6: school fant like crus.

- L7: she put me at the chockbot.

- $\quad \mathbf{L 8}$ he can aut for school you weaking for three apu to home.

In view of the importance of adequate language proficiency in the Language of Learning and Teaching (LoLT) for the learning and teaching process in Namibia, the above examples show that learners are struggling to convey meaning on a variety of levels. This is a great challenge for learners and teachers. Learners struggle to respond to exercises and tests. In addition, their lack of even basic vocabulary in the LoLT causes the following:

- When learners write or speak, they may alter the meaning they intend to bring across. As a result, they may end up omitting key elements of the information.

- Learners end up in what is commonly known as 'go off content' or 'off question' conditions. This is similar to Wolfaardt's research finding that shows that most learners do not answer examination questions correctly due to the fact that they do not understand the question asked (2004: 366).

\section{English-to-Rumanyo translation task}

Two days after the Rumanyo-to-English test, learners were given an English text to read and translate into Rumanyo. Other than testing vocabulary level, the aim of this test was to see if 
learners could produce what was read in English in Rumanyo so as to determine to what extent Rumanyo could serve as scaffolding for the development of English. Below is an example of one learner's response (see Table 3). Like in the first test, the text given to learners is provided in the left column and the learner's translation from English into Rumanyo in the right column (right). The suggested or possible Rumanyo version of the text is provided below the two columns.

\begin{tabular}{|c|c|}
\hline The text given to learners (English) & Learners translated text in Rumanyo \\
\hline $\begin{array}{l}\text { On the } 15^{\text {th }} \text { of January I will start the New } \\
\text { Year in high school. I am very glad that I } \\
\text { will pass grade } 7 \text {. I'm aiming to be in the } \\
\text { hostel and finish my grade } 12 \text { and proceed } \\
\text { to the University of Namibia (UNAM) } \\
\text { despite the hostel and school fees. }\end{array}$ & $\begin{array}{l}\text { Mwakughumumayuva gha15 murongona } \\
\text { nakavarekire mumwakawaghupe kushure } \\
\text { yakuyeruka.nahafire shiri mposhi } \\
\text { narondire muntambondunge } \\
\text { yaghutanonaviviri. nakakalire kuhostel } \\
\text { nganikamane ntambondunge yamurongo } \\
\text { naviviri nakuUNAM nakufutaku hostel } \\
\text { nakushure (Learner 1). } \\
\text { Mumayuva } 15 \text { gha Murongona ngani } \\
\text { vareka na mwaka waghupe kushure. Ame } \\
\text { na kughayara ashi nganironda } \\
\text { ntambondunge ya } 7 . \text { Ame nganihafa } \\
\text { kukara mu hostel ntani nganimanite } \\
\text { ntambondunge yaghu } 12 \text { ntani ngani yend } \\
\text { ku UNAM. Nganishure hostel na shure } \\
\text { fees (Learner 3). } \\
\text { Mumayu 15 Murongona ame ngani vareka } \\
\text { shure ame nganironda ntambondunge } 7 \\
\text { ame nganiyenda kuhostel ngani kamanite } \\
\text { ntambondunge ya 12 makura ngani yenda } \\
\text { ku UNAM (Learner 6). }\end{array}$ \\
\hline
\end{tabular}

\section{The possible or suggested translated text (Rumanyo)}

Mumayuva gha 15 gha mwedi wa Murongona ngani kavareka mwaka waghupe kushure yakureruka. Ame nahafa/kuna kara naruhafo morwa ngani ronda/pita ntambondunge ya 7. Kuna kughayara kukara muhostera mposhi ngani kapite ntambondunge ya 12 makura ngani yende kushure kurona UNAM kughupako mfuto ya shure nayi ya kuhostera.

\section{Table 3: English-to-Rumanyo translation}

Graph 2 shows that most of the learners understood quite clearly what the text was all about. The analysis was once again done for accuracy and for interpretation. 


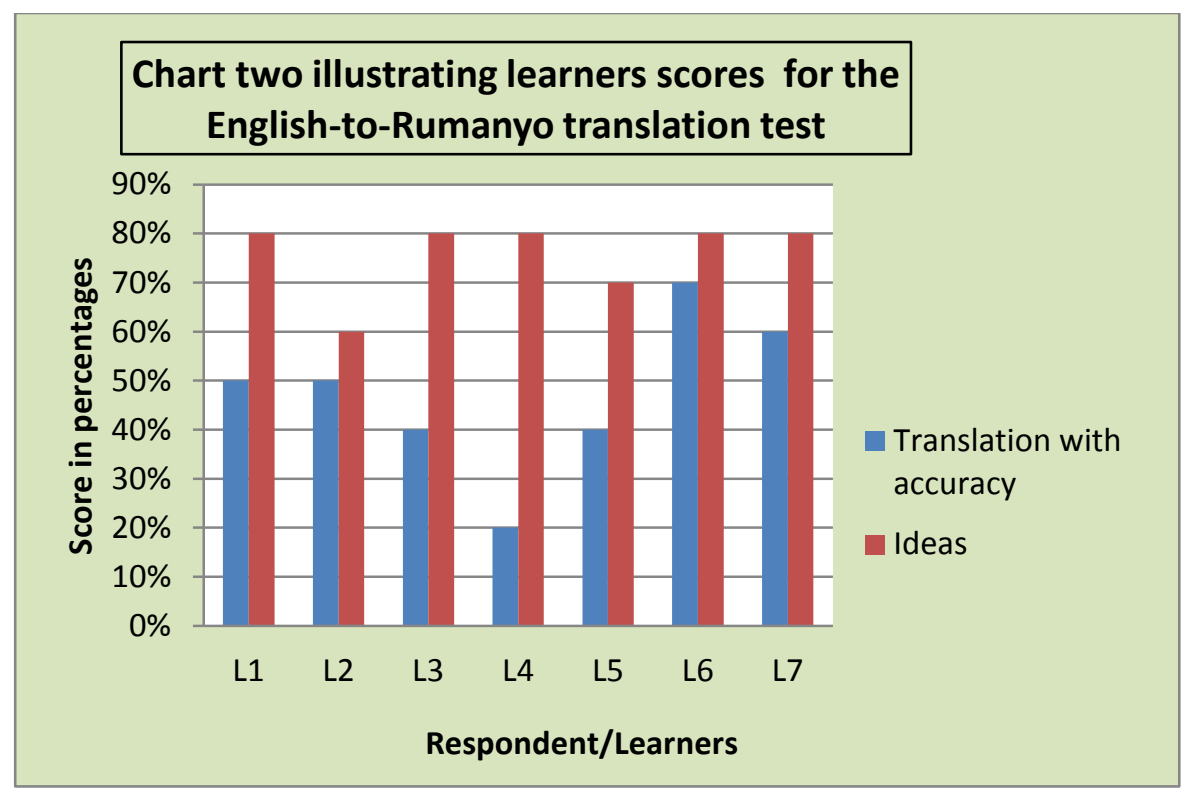

Graph 2: Illustration of Learner's ability to translate and express ideas from English in Rumanyo.

Compared to Graph A (Rumanyo-to-English translation), Graph B shows that four out of seven learners scored above 50\% in the English-to-Rumanyo translation test for the accuracy of their Rumanyo texts. This means that learners' translations in the latter test (English-to-Rumanyo test) were better than in the former test (Rumanyo-to-English test). There were various factors that influenced learners' performance in the English to Rumanyo translation task. Some of these factors include:

- Most learners' word order in sentences was good, which was lacking in the English translations.

- They did not translate the text word by word or what is commonly known as 'direct translation', but they used understanding. For example, in the Rumanyo-to-English test, most learners did not get the wording on the 21st of July right since they translated it directly from Rumanyo, which altered the meaning of the sentence.

- Unlike in the first test, most learners used their understanding to translate the given text. For instance, in Rumanyo, the direct translation of the preposition on is $p a$ and in is $m u$. Interestingly, most learners did not use direct translation (from English to Rumanyo) when they wrote on the 15th of January. Instead, they used their understanding and produced idiomatically appropriate sentences.

The English to Rumanyo translation provides evidence of the difference between receptive and productive proficiency. As is often the case with multilinguals, the learners' receptive proficiency (in this case in English) is far better than their productive proficiency. Their written English is generally poor, but as the English to Rumanyo translation shows, the depth of their understanding of English is visible in the richness of the texts produced in Rumanyo. 
The results of both these tests show that learners' command of Rumanyo creates a possibility for the use of translanguaging, for example by comparing the two languages and focusing explicitly on differences and similarities. The way in which this can be done will be discussed next.

\section{Comparing vocabulary items}

The translation tasks provided basic information on learners' proficiency in English and Rumanyo. This information pointed to possible translanguaging strategies that would build on existing knowledge. Translanguaging in pedagogical practice is not only about code switching in bilingual classrooms, but also about the use of learners' strong language to build or develop the weaker language (Williams, 2003). During the two sessions taught by the first author, the Rumanyo words were used alongside English (see example below). In order for learners to understand the words in English better, pictures were placed next to each word. The same words and pictures were used at the next stage (grass, nature, branch, ruler and teacher), where learners were asked to construct sentences in both languages. Learners constructed their sentences orally - first in groups, then later individually. Pictures were seen as the easiest way to explain the meaning of a word to learners. Besides, pictures were also used to help learners practise speaking in a developing language (English), to say what they can see in a picture, to give specific words for the picture and to create sentences using pictures.
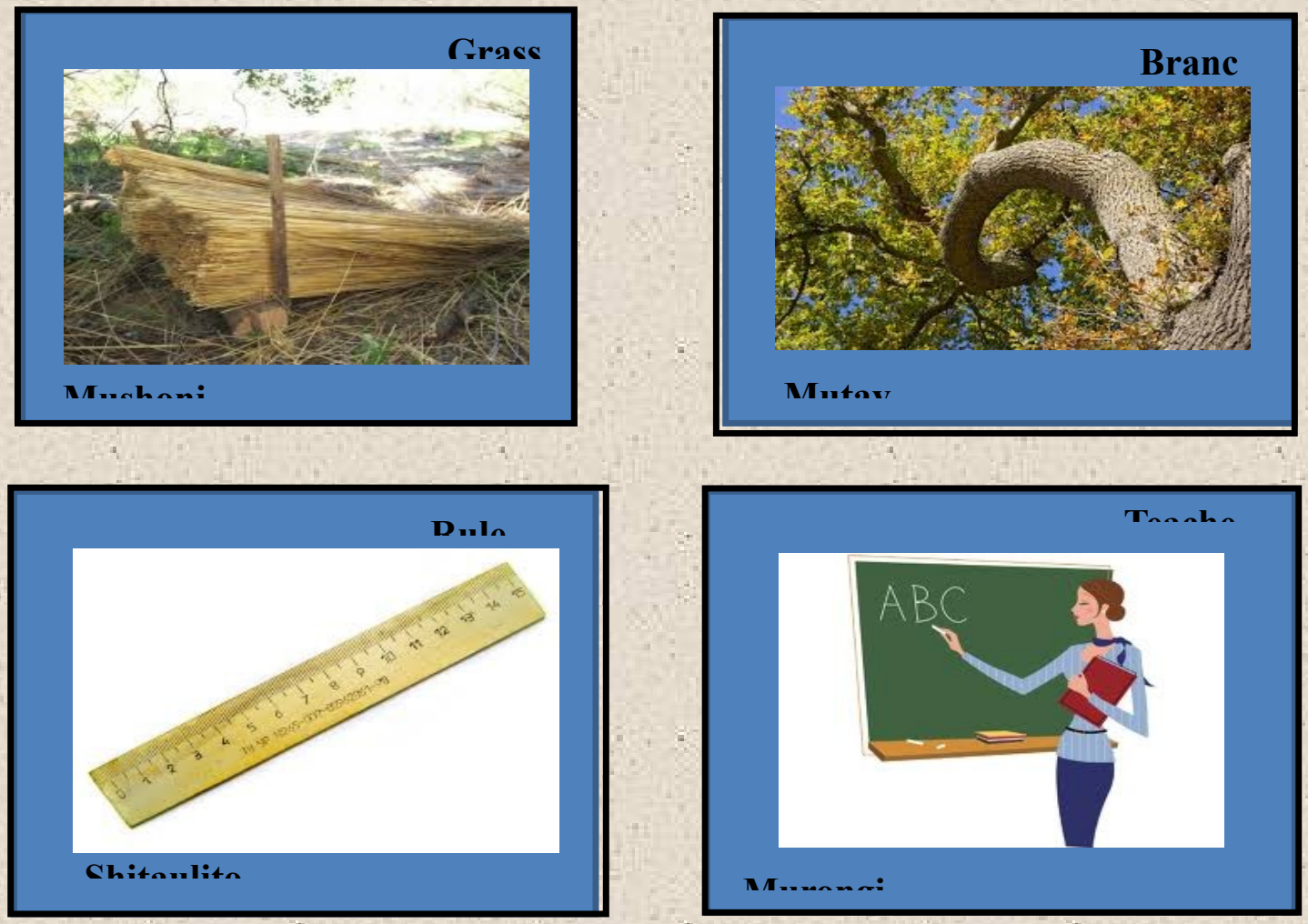

Figure 1: Picture Vocabulary Words 


\section{PREVIEW - VIEW - REVIEW APPROACH}

In another attempt to use Rumanyo as a building block, the first author used the preview - view - review approach (García, 2009: 301). This approach does not compare the languages directly at word level, but in this case exploited the possibility presented by the translation tasks, which showed that learners understood more than they could produce in English. In this approach one language is used to preview content, the other language to view it and in the final review phase, the teacher returns to the original language. Since learners' proficiency was better in Rumanyo, it was argued that content should be contextualised by previewing and reviewing it in the more familiar language. English was not avoided completely in the preview and review sessions, but was always used in direct comparison to Rumanyo equivalents.

- Preview: Rumanyo sentences were placed on the blackboard. These sentences were: a) nkangorughano-nkango dakutanta viviyaghuka, which literally translates as Verbs are actions or doing words and b) Vavo kuna kuteta mushoni, which translates as They are cutting grass. Afterwards, Rumanyo words were compared to their English translations and explained to learners. This is similar to what was done in the first lesson where L1 words were placed in parallel with L2 words. This was done as warm-up activities to prepare learners for what was coming in the English lesson.

- View: The word verb was defined and the placement of verbs and subjects in a sentence (subject and verb agreement) was discussed. Examples were given in English. Learners were also given a few activities that required them to find the right arrangement of verbs and subjects in a sentence, for example, I am going to school, They are eating, and They are cutting grass. Using pictures learners were asked to formulate sentences applying what they had learnt. This was meant to see if learners understood the word verb and the sentence structure subject-verb agreement.

- Review: The review session was not only in Rumanyo, as the strategy given by García (2009: 301) suggests. To test whether learners understood what was taught, a picture was placed on the blackboard with a Rumanyo word and learners were asked to construct sentences in English. The aim of these oral questions was to revisit the concept that was taught not only to see if learners could demonstrate productive skills, but also to check learners' understanding of the lesson content.

Based on the results of the two translation tests it was clear that it would be wasteful to avoid learners' knowledge of their first languages since this could be the main key to improving the second language. In the two sessions taught, using mainly translation and preview - view review strategies, the observation was that the use of pictures with bilingual labels improves vocabulary at least in the short run. With the encouragement from the teacher to tell learners to use specific tenses, verb agreement and so on, the impression was that the use of pictures with bilingual labels helped them to practise pronunciation, create sentences, describe the pictures and practise their linguistic repertoire (even when working in groups).

In reflecting on these lessons, the impression was that learners' behaviour showed signs of understanding (oho - a Rumanyo expression to show someone that you now understand what 
he/she is explaining) and that they were willing to participate. Unlike the practice that has also been observed by Wababa (2009), where learners' only contribution would be to chorus Yes, teacher, they engaged in the lesson and made use of Rumanyo as their reference point. For instance, when learners were asked to construct sentences based on what they had learnt, learners were observed making use of Rumanyo to find the word they were looking for.

\section{DISCUSSION}

Most grade seven learners at the rural primary school CSX lack sufficient proficiency in English - the language used for learning and teaching. This is because they are more proficient in and exposed to Rumanyo, the home and community language. In view of the importance of adequate proficiency in the LoLT for the teaching and learning process in Namibia, the findings from the translation tests show that learners are struggling to express meaning on a variety of levels. The translation tasks show that a lack of vocabulary in the LoLT results in learners altering the meaning they intend to bring across when they write or speak. As a result, they end up omitting some key elements of the information. In other words, learners are able to receive information in a home/ community language, but they are unable to produce the information in English. This is a great challenge not only for the learners but also for teachers. This suggests that learners would not be able to produce subject content knowledge and this does not bode well for their secondary school career. However, using visuals can help learners make meaning of complex academic content.

This study links up with research by Aina, Ogundele and Olanipekun (2013: 355), who prove that where English proficiency is lacking in an academic setting, it will definitely lower the academic performance of learners. If teachers can be supported to use strategies like translation (to determine language proficiency) and preview - view - review strategies as a form of more responsible code switching, learners' L1 can become a resource rather than a barrier for the learning of the powerful LoLT: English. Additionally, this study viewed the use of semiotic modes (visuals) as effective since it constitutes an important scaffolding mechanism when English is used for instruction.

This study also concludes that random switches in sentences during teaching are similar to what Cummins (2005: 585) calls the 'squandering of bilingual resources'. However, if the use of L1 is well planned, it plays the role of mediator, providing strong scaffolding that builds a bridge to the development of English in rural primary schools where learners are likely to hear and use English only in the classroom. The contextual analysis conducted in this study showed that conversational code switching between Rumanyo and English is used extensively by teachers. This means that the conditions for introducing more structured code switching are favourable and in-service training of teachers to use particular translanguaging strategies has a good chance of success. Existing code-switching practices can be seen as a base on which a more structured preview - view - review strategy can be used. The translation exercises clearly showed where learners' strengths lay. Their knowledge of Rumanyo can act as a resource for developing vocabulary in English if the two languages are compared and contrasted in purposeful ways.

As such this study was not an intervention: it tested the ground to see which existing practices can be refined and adapted to capitalise on teacher and learner bi-/multilingualism. It is only by 
systematically trying out various strategies that the possibilities of giving in-service teachers guidance for using translanguaging strategies can be determined.

\section{CONCLUSION}

Translanguaging is a term that is quite fashionable currently, but not much has been done in terms of making choices and attempting specific translanguaging strategies. At the same time it does not seem prudent to introduce such strategies without analysing the context and making sure that translanguaging strategies have a good chance to succeed. If teachers were not using code switching and learners were not used to such a strategy, it would make little sense to try and convince teachers of its usefulness. In this study the unplanned use of Rumanyo and English in the classroom as an approach lacks the systematic reinforcement of links between English and Rumanyo. However, its existence provides favourable conditions to introduce a more planned approach. Thus, this project suggests that rural primary teachers are failing to mediate content unless they use their own and learners' translanguaging skills in a more planned and focused way, such as in the translation preview - view - review strategies as well as the use of visual scaffolding. Such planned switches (responsible code switching) between Rumanyo and English could provide strong scaffolding for English development. Future analyses of texts produced by multilingual learners could also include an analysis of lexical richness in English, Rumanyo and other community languages (Daller, Van Hout and Treffers-Daller, 2003) as an indication of their proficiency in these languages. Such data will also guide researchers as to the success of translanguaging for effective learning. The most important project for the future remains a longitudinal study to determine the long-term effects of these strategies.

\section{REFERENCES}

AINA, JK, AG OGUNDELE \& SS OLANIPEKUN. 2013. Students' Proficiency in English Language Relationship with Academic Performance in Science and Technical Education. American Journal of Educational Research [online].Available from http://pubs.sciepub.com/education/1/9/2.

AUERBACH, ER. 1993. Reexamining English only in the ESL classroom. TESOL Quarterly 27 (1), 9-32.

BAKER, C.1993. Foundation of Bilingual Education and Bilingualism. Clevedon: Multilingual Matters.

BAKER, C. 2006. Foundations of bilingual Education and Bilingualism ( $4^{\text {th }}$ edition), Clevedon, UK. Multilingual Matters.

BLACKLEDGE, A \& A CREESE. 2010. Multilingualism: A Critical Perspective. University of Leeds: Continuum.

BROCK-UTNE, B. 2007. Language of Instruction and Student Performance: New Insight from Research in Tanzania and South Africa. International Review of Education. Springer, 53 (5/6):509-530. 
CELIC, C \& K SELTZER. 2011. Translanguaging: A CUNY-NYSIEB guide for educators. New York: CUNY-NYSIEB, The Graduate Center, The City University of New York.

CLEGG, J \& O AFITSKA. 2011. Teaching and Learning in two Languages in African Classroom, Comparative Education, UK, Routledge, 47 (1): 61-77.

CUMMINS, J. 2005. A proposal for action: strategies for recognizing heritage language competence as a learning resource within the mainstream classroom. Modern Language Journal, 89: 585-592.

DALLER, H, R VAN HOUT \& J TREFFERS-DALLER. 2003. Lexical Richness in the Spontaneous Speech of Bilinguals. Applied Linguistics 24 (2):197-222.

GARCÍA, O. 2009. Bilingual Education in the 21st Century: A Global Perspective. London: Wiley/Basil Blackwell.

HARRIS, P. 2011. Language in schools in Namibia: The missing link in educational achievement? Monograph No. 1:1-76.Windhoek: The Urban Trust of Namibia.

HORNBERGER, NH \& H LINK. 2012. Translanguaging in today's classrooms: A biliteracy lens. Theory into practice. Routledge, 51(4):239-247.

HOSHINO, N, \& G THIERRY. 2011. Language selection in bilingual word production: Electrophysiological evidence for cross-language competition. Brian Research, 1371, 100-109.

IYAMBO, A. 2011. Minister of Education speech at the Poetics and Linguistics Association Conference. Polytechnic of Namibia. Windhoek.

LEWIS, G, B JONES \& C BAKER. 2012. Translanguaging: developing its conceptualisation and contextualisation. Educational Research and Evaluation: An International Journal on Theory and Practice, 18(7):655-670.

MINISTRY OF EDUCATION AND CULTURE. 1993. Towards Education For All: A Development Brief for Education, Culture and Training. Namibia: Gamsberg Macmillan.

MURRAY, C. 2007. Reflections on the question of mother tongue instruction in Namibia. NAWA Journal of Language and Communication [Online]. Available from http://ir.polytechnic.edu.na/bitstream/10628/120/1/Murray.\%20Reflections\%20on\%20the \%20question\%20of.pdf. [Accessed: 2 October 2014]

PROBYN, M. 2001. Teachers Voices: Teachers Reflections on Learning and Teaching through the Medium of English as an Additional Language in South Africa. International Journal of Bilingual Education and Bilingualism, 4(4):249-266.

ROSE, S. \& O VAN DULM. 2006. Functions of code switching in multilingual classrooms. Per linguam 22(2): 1-13.

SETATI, M, J ADLER, Y REED, \& A BAPOO. 2002. Incomplete journeys: Code-switching and other language practices in Mathematics, Science and English language classrooms in South Africa. Language and Education, 16(2):128-149.

SHOHAMY, E. 2006. Language policy: hidden agendas and new approaches. London: Routledge.

STEPHEN, DF, JC WELMAN \& WJ JORDAAN. 2004. English language proficiency as an indicator of academic performance at a tertiary institution. SA Journal of Human Resource Management, 2(3):42-53.

THIERRY, G \& YJ WU. 2007. Brain potentials reveal unconscious translation during foreign language comprehension. Proceedings of the National Academy of Sciences, USA: 104, 12530-12535. 
VAN DER WALT, C, R MABULE \& JJ DE BEER. 2001. Letting the L1 in the back door: Code-switching and translation in Science, Mathematics and Biology classes. Language Teaching Journal, 35(2-3): 123-134.

VINKE, AA \& WMG JOCHEMS. 1993. English proficiency and academic success in international postgraduate education. Higher Education. Netherlands, Kluwer Academic, 26:275-285.

WABABA, Z. 2009. How Scientific Terms are Taught and Learnt in the Intermediate Phase. M Ed dissertation. Available from http://hdl.handle.net/10019.1/2189 [Accessed: ??]

WILLIAMS, C. 2003. 'Defnyddio trawsieithu í ddatbly llythrennedd deuol [Using translanguaging to develop dual literacy].' In G Roberys \& C Williams (eds.), Addysg Gymraeg-Addysg Gymreig, pp. 288-312.Bangor, UK: School of Education.

WILSON, J \& SC KOMBA. 2012. The Link between English Language Proficiency and Academic Performance: A Pedagogical Perspective in Tanzanian Secondary Schools. World Journal of English Language, 2 (4):1-10.

WOLFAARDT, D. 2004. 'The Influence of English in the Namibian Examination Context.' Symposium Proceedings: 366-374.

WOLFAARDT, D. 2005. Namibia: A Case for a Gradual Transitional Bilingual Language Programme. Proceedings of the $4^{\text {th }}$ International Symposium on Bilingualism: 23572366. Same.

\section{BIOGRAPHICAL NOTES}

Nangura Mwinda obtained an M Ed degree at Stellenbosch University in March 2015. She is currently a teacher in the Kavango region of Namibia. E-mail address: rmwinda@gmail.com

Christa van der Walt is professor in the Department Curriculum Studies at Stellenbosch University and does research in multilingual education. Email address: cvdwalt@,sun.ac.za

\footnotetext{
'The term Language of Learning and Teaching (LoLT) is used rather than language of instruction or medium of instruction (as known in Namibia), since LoLT refers to the language used for both teaching and learning.

ii National languages in Namibia refers to the thirteen languages the government recognises or the written languages with standardised orthography. These languages include: (1) Afrikaans, (2) English, (3) German, (4) Ju/hoansi, (5) Khoekhoegowab, (6) Oshikwanyama, (7) Oshindonga, (8) Otjiherero, (9) Rukwangali, (10) Rumanyo, (11) Setswana, (12) Silozi, (13) sign language and (14) Thimbukushu.

iii As it was before the country's independence .

iv One of the endangered languages in Kavango.

${ }^{\vee}$ A spoken language of solidarity as well as for wider communication in the Ndiyona constituency, also known as Rumanyo in school context. Being the language of wider communication (for both native and non-native speaker) in the afore-mentioned constituency, Rugciriku also plays a role of a lingua franca.

vi Learners' written consent was not considered since the project took place during school hours and did not contain harmful experiments. However, written permissions to carry out the project was granted to the author by the research ethnic committee (rec) at the University of Stellenbosch (South Africa), the director of education in the Kavango region of Namibia, the principal and the class teacher at CSX school.
} 